\title{
French patients on daily hemodialysis: clinical characteristics and treatment trajectories
}

\author{
Adélaïde Pladys ${ }^{1,2^{*}}$, Sahar Bayat ${ }^{1,3}$, Anne Kolko ${ }^{4}$, Clémence Béchade ${ }^{5,6}$, Cécile Couchoud ${ }^{7}$, Cécile Vigneau ${ }^{2,8}$ and on \\ behalf of the REIN registry
}

\begin{abstract}
Background: Increasing the weekly frequency of hemodialysis sessions has positive effects, on the control of several biological data of patients. However, knowledge about Daily HemoDialysis (DHD) practices is limited in France. The aim of the present study was to describe the characteristics and treatment trajectories of all French patients undergoing DHD.

Methods: All patients older than 18 years who started DHD between 2003 and 2012 in France were included and followed until December 31, 2013. The patients' demographic and clinical characteristics and treatment modalities were extracted from the French Renal Epidemiological and Information Network (REIN) registry.

Results: During the inclusion period, 753 patients started DHD in France. Based on their median age (64 years), patients were classified in two groups: "old" group ( $\geq 64$ years) and "young" group ( $<64$ years). Patients in the old group had more comorbidities than in the young group: $48 \%$ had diabetes (vs $29 \%$ in the young group), $17 \%$ an active malignancy (vs $10 \%$ ) and $80 \% \geq 1$ cardiovascular disease (vs $41 \%$ ). Concerning patients' treatment trajectories, 496 (66 \%) patients started with another dialysis before switching to DHD and 257 (34\%) directly with DHD. At the end of the follow-up, $69 \%$ of patients in the old group were dead (27.4\% in the young group) and kidney transplantation was more frequent in the young group (30.4\% vs $0.5 \%$ ).

Conclusion: In France, DHD is proposed not only to young in rather good clinical conditions and waiting for kidney transplantation, but also to old and frail patients with higher mortality.
\end{abstract}

Keywords: Daily hemodialysis, End stage renal disease, Patient profiles, Patients trajectories, REIN registry

\section{Background}

End Stage Renal Disease (ESRD) is a chronic progressive disease and a major public health issue as indicated by the dramatic increase in the number of patients treated for ESRD worldwide and also in France [1,2].

Hemodialysis (HD), three times per week, is the most frequent renal replacement therapy (RRT) [3]. However, in recent years, new HD regimens characterized by changes in the weekly frequency [4-9], the session's duration [6-10] or the dialysis doses $[8,10-14]$ have been assessed. The main aim of these modifications was to

\footnotetext{
* Correspondence: adelaide.pladys@ehesp.fr

${ }^{1}$ EHESP Rennes, Sorbonne Paris Cité, Rennes, France

${ }^{2}$ Université Rennes 1, UMR CNRS 6290, Rennes, France

Full list of author information is available at the end of the article
}

reduce the side effects of thrice-weekly $\operatorname{HD}[4,8,15]$ that are caused by the fluctuations in the level of urea particles and their toxicity between HD sessions [4, 6, 15-19], and also to improve the patients' quality of life $[4,8,10,11,20,21]$ by decreasing the number/duration of sessions and improving blood purification [20-22].

Some studies have shown that increasing the weekly frequency of dialysis sessions is the best approach to reproduce the kidney physiological functional role, compared to three times/week HD [5, 15, 18, 23]. For instance, Daily HemoDialysis (DHD) consists of more sessions per week $(\geq 5)$, delivered either as shorter daily sessions $(1.5-3 \mathrm{~h})[4,8,14,15,24]$ or as longer nocturnal sessions $(\geq 5 \mathrm{~h})[4,8,14,15,23,24]$. Some studies on 
DHD showed that the increased weekly frequency of dialysis has positive effects on the control of blood pressure $[4,8,14,19,20,23,24]$, uremia $[6,10,15,19]$ and ventricular hypertrophy $[8,14,23-26]$ in patients with ESRD.

Several studies have also analyzed DHD effects on survival [22, 23, 27-30]. Although most of them found that survival was improved in patients undergoing DHD [22, 28-30], the study by Suri et al. reported that the mortality rate was significantly higher among patients treated with DHD than in those who received conventional $\mathrm{HD}$ in in-center $\mathrm{HD}$ services [27]. These authors used data from the International Quotidian Dialysis Registry (IQDR) that includes data from many different registries, such as the French Renal Epidemiological and Information Network (REIN) registry. As two-thirds of the data of this study were extracted from the REIN registry, the patients were mainly French, differently from other studies where data, and thus patients, were mainly from the American USRDS database [22, 28, 30]. Therefore, Suri and colleagues hypothesized that the French patients on DHD were older and with more comorbid conditions than patients on conventional HD [27].

In France, patients undergoing DHD represented $1 \%$ of all prevalent cases in 2012 with regional disparities ranging from 0 to $6 \%$ [31]. However, and as mentioned by Suri and colleagues, there are few information on DHD practice and on the demographic and clinical characteristics of the patients undergoing DHD in France. Moreover, the reasons leading to choose DHD among the different RRT options are not described. Nevertheless, literature data suggest that in France, DHD is proposed both to young/active and old/frail patients.

Therefore, to better understand DHD practice in France and in a view of future establishment of recommendations for DHD by the nephrologist community, the aim of this study was to determine the demographic and clinical characteristics of patients on DHD. In addition, the treatment trajectories before starting such a treatment and also the different DHD protocols currently proposed in France will be studied.

\section{Methods}

\section{Study population}

The French REIN registry includes all patients with ESRD undergoing RRT, dialysis or transplantation and living in France. The registry was established in 2002 and since 2011 it covers the entire French territory. The registry organization has been described in details elsewhere [32].

This study was a retrospective analysis of data collected in the REIN registry. For this work, we included all patients aged 18 years and over who started DHD in the French regions included in the REIN registry between January 1, 2003 and December 31, 2012. We excluded patients who initiated RRT in a French region before the introduction of the registry (left truncated data), those who received pre-emptive renal transplantation and those undergoing DHD seven days per week. Each patient was then followed until death or the study end point (December 31, 2013).

\section{Data collection \\ Patients' and HD characteristics}

To describe the patients' characteristics at the first DHD, two types of variables were collected: i) demographic data: sex, age; ii) clinical data: smoking status (current/ former smoker and never smoked); Body Mass Index (BMI); hemoglobin and albumin levels; comorbidities and disabilities, such as cardiovascular diseases (coronary artery disease, peripheral vascular disease, congestive heart failure, arrhythmia, aneurism and cerebrovascular disease), active malignancy, cirrhosis, respiratory disease, physical or psychiatric disabilities and walking disability (walks without help, needs partial assistance for transfers, totally dependent for transfers). All clinical data were collected at RRT initiation, then annually. Quantitative variables were grouped in clinically relevant classes.

DHD characteristics were described as: i) treatment modality: conventional (hemodialysis) HD and DHD, convective (hemodiafiltration, hemofiltration, biofiltration) $\mathrm{HD}$ and DHD, peritoneal dialysis (PD); ii) treatment implementation autonomy: autonomous (home and HD in satellite units and non-assisted PD), and non-autonomous dialysis (nurse-assisted PD, in-center HD; iii) number of weekly sessions and duration of each session; iv) vascular access (catheter, arterio-venous fistula, bypass); v) DHD environment: in-center unit (hospital-based or medically supervised unit); satellite unit (self-care or nurse-assisted) and at home; vi) emergency start vs planned first dialysis session. Treatment modalities were collected at RRT initiation and every time the treatment modality was changed.

\section{Treatment trajectories}

To describe the patients' treatment trajectories before DHD initiation, several data included in the REIN registry were used: i) date of the first RRT and treatment modalities; ii) dialysis modality changes before DHD; iii) date of DHD initiation. Additionally, the clinical outcome at the end of the follow-up period (31/12/2013) was included: death; DHD; switch to $<5$ sessions/week HD; PD; and kidney transplantation.

\section{Statistical analysis}

The patients' characteristics at DHD initiation were expressed as frequencies and percentages for categorical variables, and as median and interquartile values (IQR) for continuous variables. Demographic and clinical 
features as well as DHD modalities were described by subgroups, based on the population's median age, and according to the treatment trajectories before DHD initiation (patients directly on DHD and patients who had other RRT before switching to DHD). The patients' treatment trajectories after DHD initiation were also described. The characteristics of different subgroups were compared using a Khi-square test.

Patient survival and the access to renal transplantation were assessed from dialysis initiation until death or December, 31 2013. Kaplan Meier survival curves have been established. The Cox regression was applied to evaluate the association between patients' characteristics and death in the total population and the access to renal transplantation for patients less than 80 years. All variables associated with outcomes in unadjusted model $(p<0.2)$ were included in an adjusted one. All variables presenting a $p$-value $<0.05$ in final adjusted model were considered as statistically significant.

Statistical analyses were performed with the Stata 11.1 software (College Station, TX).

\section{Results}

Between 2003 and 2012, 753 patients aged 18 years and over started DHD in the 26 French regions contributing to the REIN registry.

\section{Demographic and clinical features}

Table 1(a) and (b) summarize the demographic and clinical characteristics of patients on DHD. Their mean age at DHD initiation was $62 \pm 17.7$ years and $63.5 \%$ of them were male. Many patients had one or more comorbidities at DHD start: diabetes (38.6\% of all patients), respiratory disease $(15.4 \%)$, active malignancy (13.4\%), one or more cardiovascular diseases $(60 \%)$, or physical or psychiatric disabilities (19.5\%).

Then, patients were divided in two groups based on their median age at DHD initiation (64 years; Additional file 1: Figure S1): young $(<64$ years; $n=376)$ and old ( $\geq 64$ years; $n=377$ ) group. The patients' mean age in the young group was $47.2 \pm 12$ years and in the old group was $76.6 \pm 7$ years. As expected, more patients in the old group had comorbidities than in the young group (Table 1(b)): diabetes $(48.3 \%$ vs $29 \%, p<0.001)$, active malignancy ( $17.2 \%$ vs $9.6 \%, p=0.002)$, one or more cardiovascular disease $(80 \%$ vs $40 \%, p<0.001)$ and had more frequently severe walking disabilities $(12.7 \% v s$ $6 \%, p<0.001)$.

\section{Patients' treatment trajectories before starting DHD}

Then, patients were divided in two groups based on their pre-DHD trajectory: patients who started RRT directly with DHD (dDHD; $n=257$ ) and patients who started with other RRT before switching to DHD (sDHD; $n=496)$.
The percentage of patients aged $\geq 64$ years was higher in the $\mathrm{dDHD}$ than in the sDHD group (62\% vs $44 \%)$ as well as the proportion of patients with comorbidities or in bad clinical conditions (Table 2). Specifically, albumin levels were $<30 \mathrm{~g} / \mathrm{dl}$ in $33.5 \%$ of patients in the dDHD group ( $v s$ $13.7 \%$ in the sDHD group) and hemoglobin levels $<10 \mathrm{~g} / \mathrm{dl}$ were detected in $47.9 \%$ of patients in the dDHD group ( $v s 23 \%$ in the sDHD group). Moreover, more patients in the dDHD group had an active malignancy ( $18.3 \%$ vs $10.9 \%$ in the sDHD group, $p<0.001$ ) or serious walking disabilities (16.3 \% vs $5.8 \%$ in the sDHD group, $p<0.001$ ).

Patient in the SDHD group switched to DHD after a median RRT duration of 2 years (IQR: 1-3.8). During this period, 27 (5.4\%) changed at least once their dialysis modality. Specifically, 19 patients switched from PD to $\mathrm{HD}$ and eight patients from HD to PD. Only three patients changed twice their treatment modality before switching to DHD. Conventional HD was the pre-DHD treatment of choice among patients in the sDHD group ( $82.7 \% ; n=410)$, followed by PD (9.9\%; $n=49)$ and convective HD $(7.5 \% ; n=37)$. Moreover, non-autonomous dialysis, mainly in-center dialysis requiring partial or total nurse assistance, was frequent in the sDHD group (79 \% of patients).

\section{DHD regimens}

At DHD initiation, 602 patients $(80 \%)$ had conventional DHD (Table 3) with five sessions/week (24.4\%) or six sessions/week (55.6 \%). The others (20 \%) had five sessions/ week (5.6 \%) or six sessions/week (14.4\%) of convective DHD. The session's median duration was $3 \mathrm{~h}$ (IQR: 2-3). Only seven patients had sessions longer than five hours.

Among the patients in the dDHD group, 146 (57 \%) initiated DHD in emergency conditions compared to 140 (28 \%) in the sDHD group. Patients in the dDHD group had dialysis mainly in in-center HD services (92.6\%), while patients in the sDHD group were dialyzed more often in satellite units $(29.6 \%)$ or at home $(8.1 \%)$.

\section{Clinical outcome at the end of the study}

Patients underwent DHD for a median duration of 258 days (IQR: $52-487$ ). At 12/31/2013, 363 patients were dead (48.2\%), 141 patients (18.8\%) were still on DHD, $14.7 \%$ underwent kidney transplantation, $17.3 \%$ switched to HD ( $<5$ sessions per week) and $1.1 \%$ to PD (Fig. 1).

\section{Survival}

The percentage of patients who died was higher in the old group $(69 \%)$ than in the young group $(27.4 \%)$ and dDHD patients died in higher proportion than sDHD ones $(60.3 \%$ vs $42 \%)$. The risk of dying at 2 years after dialysis initiation was approximately of $12 \%$ in sDHD patients and of $50 \%$ in dDHD ones (Additional file 1: 
Table 1 Demographical, biological (a) and clinical characteristics (b) at DHD initiation: whole population of patients with ESRD and young and old group based on the median age ( $<64$ vs $\geq 64$ years)

\begin{tabular}{|c|c|c|c|c|}
\hline \multirow[t]{3}{*}{ (a) } & Whole population & $<64$ years & $\geq 64$ years & \\
\hline & $(n=753)$ & $(n=376)$ & $(n=377)$ & \\
\hline & n (\%) & n (\%) & n (\%) & $p$ \\
\hline \multicolumn{4}{|l|}{ Gender } & 0.42 \\
\hline Male & $478(63.5)$ & $244(35)$ & $234(62)$ & \\
\hline Female & $275(36.5)$ & $132(65)$ & $143(38)$ & \\
\hline \multicolumn{4}{|l|}{ BMI $\left(\mathrm{kg} / \mathrm{m}^{2}\right)^{\mathrm{a}}$} & 0.40 \\
\hline$<18.5$ & $50(6.6)$ & $31(8.2)$ & $19(5)$ & \\
\hline $18.5-23$ & $158(21)$ & $82(21.8)$ & $76(20.2)$ & \\
\hline $23-25$ & 105 (13.9) & $53(14.2)$ & $52(13.8)$ & \\
\hline$\geq 25$ & $330(43.8)$ & $158(42)$ & $172(45.6)$ & \\
\hline Missing & $110(14.6)$ & $52(13.8)$ & $58(15.4)$ & \\
\hline \multicolumn{4}{|l|}{ Albumin (g/dl) } & $<0.001$ \\
\hline$<30$ & $154(20.5)$ & $54(14.4)$ & $100(26.5)$ & \\
\hline$\geq 30$ & $490(65.1)$ & $265(70.5)$ & $225(59.7)$ & \\
\hline Missing & $109(14.5)$ & $57(15.2)$ & $52(13.8)$ & \\
\hline \multicolumn{4}{|l|}{ Hemoglobin (g/dl) } & 0.26 \\
\hline$<10$ & $237(31.5)$ & $118(31.4)$ & 119 (31.6) & \\
\hline $10-12$ & $295(39.2)$ & $137(36.4)$ & $158(41.9)$ & \\
\hline$>12$ & $172(22.8)$ & $92(24.5)$ & $80(21.2)$ & \\
\hline Missing & $49(6.5)$ & $29(7.7)$ & $20(5.3)$ & \\
\hline \multicolumn{4}{|l|}{ Smoking status } & 0.02 \\
\hline Current/former smokers & $305(40.5)$ & $166(44)$ & $139(37)$ & \\
\hline Never smoker & 366 (48.6) & $180(48)$ & $186(49.3)$ & \\
\hline Missing & $82(10.9)$ & $30(8)$ & $52(13.7)$ & \\
\hline \multirow[t]{3}{*}{ (b) } & Whole population & $<64$ years & $\geq 64$ years & \\
\hline & $(n=753)$ & $(n=376)$ & $(n=377)$ & \\
\hline & n (\%) & n (\%) & n (\%) & $p$ \\
\hline \multicolumn{4}{|l|}{ Diabetes } & $<0.001$ \\
\hline Yes & $291(38.7)$ & $109(29)$ & $182(48.3)$ & \\
\hline No & $455(60.4)$ & $265(70.5)$ & $190(50.4)$ & \\
\hline Missing & $7(0.9)$ & $2(0.5)$ & $5(1.3)$ & \\
\hline \multicolumn{4}{|l|}{ Active malignancy ${ }^{\mathrm{b}}$} & 0.002 \\
\hline Yes & $101(13.4)$ & $36(9.6)$ & $65(17.2)$ & \\
\hline No & $638(84.7)$ & $336(89.4)$ & $302(80)$ & \\
\hline Missing & $14(1.9)$ & $1(1)$ & $10(2.8)$ & \\
\hline \multicolumn{4}{|l|}{ Respiratory Disease } & 0.01 \\
\hline Yes & $116(15.4)$ & $45(12)$ & $71(18.8)$ & \\
\hline No & $620(82.3)$ & $325(86.4)$ & $295(78.2)$ & \\
\hline Missing & $17(2.3)$ & $6(1.6)$ & $11(3)$ & \\
\hline
\end{tabular}


Table 1 Demographical, biological (a) and clinical characteristics (b) at DHD initiation: whole population of patients with ESRD and young and old group based on the median age ( $<64$ vs $\geq 64$ years) (Continued)

\begin{tabular}{|c|c|c|c|c|}
\hline Hepatic disease & & & & 0.10 \\
\hline Yes & $24(3.2)$ & $14(3.7)$ & $10(2.6)$ & \\
\hline No & $713(94.7)$ & $358(95.3)$ & $355(94.2)$ & \\
\hline Missing & $16(2.1)$ & $4(1)$ & $12(3.2)$ & \\
\hline Cardiovascular Disease $^{c}$ & & & & $<0.001$ \\
\hline 0 & $297(39.4)$ & $222(59)$ & $75(20)$ & \\
\hline 1 & $160(21.2)$ & $69(18.4)$ & $91(24)$ & \\
\hline 2 & $125(16.6)$ & $36(9.6)$ & $89(23.6)$ & \\
\hline$>2$ & $171(22.7)$ & $49(13)$ & $122(32.4)$ & \\
\hline Physical and/or Psychiatric Disabilities & & & & 0.10 \\
\hline Yes & $147(19.5)$ & $73(19.4)$ & $74(19.5)$ & \\
\hline No & $567(75.3)$ & $290(77)$ & $277(73.5)$ & \\
\hline Missing & $39(5.2)$ & $13(3.5)$ & $26(7)$ & \\
\hline Walking disability & & & & $<0.001$ \\
\hline Walks without help & $502(66.7)$ & $299(79.6)$ & $203(53.8)$ & \\
\hline Totally dependent for transfer & $71(9.4)$ & $23(6)$ & $48(12.7)$ & \\
\hline Needs assistance for transfer & $92(12.2)$ & $19(5)$ & $73(19.5)$ & \\
\hline Missing & $88(11.7)$ & $35(9.4)$ & $53(14)$ & \\
\hline Treatment modality ${ }^{d}$ & & & & $<0.001$ \\
\hline SDHD & $496(66)$ & $278(74)$ & $218(58)$ & \\
\hline $\mathrm{dDHD}$ & 257 (34) & $98(26)$ & $159(42)$ & \\
\hline
\end{tabular}

${ }^{\mathrm{a} B M I}$ Body Mass Index

${ }^{b}$ Active malignancy: solid tumors or hematological malignancies; ${ }^{c}$ Cardiovascular Disease: myocardial infarction, arrhythmias, coronary insufficiency, heart failure, arteritis of the lower limbs, cerebrovascular accident; ${ }^{d} \mathrm{sDHD}$ : patients who switched to DHD after other dialysis modalities; dDHD: patients who started directly with DHD

Figure S2 (a)). The mortality rate was high among old dDHD patients (Additional file 1: Figure S2 (b)). As expected, all major comorbidities were associated with an increased risk of death. In addition, there was a significant increased risk of death for dDHD (HR = $2.9195 \%$ CI: 2.36-3.6) and this association remained significant in the adjusted model (Additional file 1: Table S1).

\section{Renal transplantation}

Patients older than 80 years $(n=102 ; 13.5 \%)$ were excluded from the analysis of the access to renal transplantation. During the follow-up, 37/205 dDHD (18 \%) and 102/446 sDHD (23 \%) patients were transplanted. dDHD patients had a higher access to renal transplantation (Additional file 1: Figure S3 (a)) in the unadjusted as in the adjusted Cox model ( $\mathrm{HR}=2.0395 \% \mathrm{CI}$ : 1.38-3.0; Additional file 1: Table S2), and especially patients $<64$ years (Additional file 1: Figure S3 (b)).

\section{Discussion}

This first study on all French patients who started DHD between 2003 and 2012 shows the heterogeneity of the demographic/clinical features and treatment trajectories of this population. Our results indicate that in France, DHD is proposed to old and frail patients with comorbidities who died in high proportion and also to young patients with ESRD who are waiting for kidney transplantation. Moreover, based on their treatment trajectory, patients could be divided in two groups: patients who started directly with DHD (older and with many comorbidities) and patients who started with other RRT before switching to DHD (younger, healthier and waiting for renal transplantation). Finally, our analysis shows that DHD modalities in France are various and depend on the individual patient's characteristics and pre-DHD treatment trajectories. The heterogeneity of the profile of French patients undergoing DHD could partially explain the contradicting results on mortality in DHD reported by Suri and colleagues [27] compared to other studies [22, 28-30].

The present work is the first study to include patients with ESRD on DHD from all France regions over a long period. To characterize this population, all major comorbidities and disabilities were taken into account. Additionally, the REIN registry includes also data on the treatment modalities as well as on the pre- and post- 
Table 2 Demographic, biological characteristics (a) and comorbidities (b) of patients based on their treatment trajectory (sDHD and dDHD) at DHD initiation

\begin{tabular}{|c|c|c|c|}
\hline \multirow[t]{3}{*}{ (a) } & sDHD patients & $\mathrm{dDHD}_{\text {patients }}{ }^{\mathrm{d}}$ & \\
\hline & $(n=496)$ & $(n=257)$ & \\
\hline & n (\%) & n (\%) & $p$ \\
\hline \multicolumn{3}{|l|}{ Gender } & 0.002 \\
\hline Male & $330(66.5)$ & $148(57.6)$ & \\
\hline Female & $166(33.5)$ & $109(42.4)$ & \\
\hline \multicolumn{3}{|l|}{ Age (years) } & $<0.001$ \\
\hline$<64$ & $278(56)$ & $98(38)$ & \\
\hline$\geq 64$ & $218(44)$ & $159(62)$ & \\
\hline \multicolumn{3}{|l|}{ BMI $\left(\mathrm{kg} / \mathrm{m}^{2}\right)^{\mathrm{a}}$} & $<0.001$ \\
\hline$<18.5$ & $27(5.4)$ & $23(8.9)$ & \\
\hline $18.5-23$ & $106(21.4)$ & $52(20.2)$ & \\
\hline $23-25$ & $70(14.1)$ & 35 (13.6) & \\
\hline$\geq 25$ & $249(50.2)$ & $81(31.5)$ & \\
\hline Missing & $44(8.9)$ & $66(25.7)$ & \\
\hline \multicolumn{3}{|l|}{ Albumin (g/dl) } & $<0.001$ \\
\hline$<30$ & $68(13.7)$ & $86(33.5)$ & \\
\hline$\geq 30$ & $374(75.4)$ & $116(45.1)$ & \\
\hline Missing & $54(10.9)$ & $55(21.4)$ & \\
\hline \multicolumn{3}{|l|}{ Hemoglobin (g/dl) } & $<0.001$ \\
\hline$<10$ & $114(23)$ & $123(47.9)$ & \\
\hline $10-12$ & $226(45.6)$ & $69(26.8)$ & \\
\hline$>12$ & $135(27.2)$ & $37(14.4)$ & \\
\hline Missing & $21(4.2)$ & $28(10.9)$ & \\
\hline \multicolumn{3}{|l|}{ Smoking status } & 0.003 \\
\hline Current/former smokers & $220(44.4)$ & $85(33.1)$ & \\
\hline Never smoker & $232(46.8)$ & $134(52.1)$ & \\
\hline Missing & $44(8.9)$ & $38(14.8)$ & \\
\hline \multirow[t]{3}{*}{ (b) } & sDHD patients & dDHD patients ${ }^{d}$ & \\
\hline & $(n=496)$ & $(n=257)$ & \\
\hline & n (\%) & n (\%) & $p$ \\
\hline \multicolumn{3}{|l|}{ Diabetes } & 0.001 \\
\hline Yes & $194(39)$ & 97 (37.7) & \\
\hline No & $302(61)$ & $153(59.5)$ & \\
\hline Missing & $0(0)$ & $7(2.7)$ & \\
\hline \multicolumn{3}{|l|}{ Active malignancy ${ }^{\mathrm{b}}$} & $<0.001$ \\
\hline Yes & $54(10.9)$ & $47(18.3)$ & \\
\hline No & $439(88.5)$ & $199(77.4)$ & \\
\hline Missing & $3(0.6)$ & $11(4.3)$ & \\
\hline \multicolumn{3}{|l|}{ Respiratory Disease } & $<0.001$ \\
\hline Yes & $81(16.3)$ & 35 (13.6) & \\
\hline No & $412(83.1)$ & $208(80.9)$ & \\
\hline Missing & $3(0.6)$ & $14(5.4)$ & \\
\hline
\end{tabular}


Table 2 Demographic, biological characteristics (a) and comorbidities (b) of patients based on their treatment trajectory (sDHD and $\mathrm{dDHD}$ ) at DHD initiation (Continued)

\begin{tabular}{|c|c|c|c|}
\hline Hepatic disease & & & $<0.001$ \\
\hline Yes & $17(3.4)$ & $7(2.7)$ & \\
\hline No & $476(96)$ & $237(92.2)$ & \\
\hline Missing & $3(0.6)$ & $13(5.1)$ & \\
\hline Cardiovascular Disease $^{c}$ & & & 0.25 \\
\hline 0 & $206(41.5)$ & $91(35.4)$ & \\
\hline 1 & $96(19.4)$ & $64(24.9)$ & \\
\hline 2 & $82(16.5)$ & $43(16.7)$ & \\
\hline$>2$ & $112(22.6)$ & $59(23)$ & \\
\hline Physical and/or Psychiatric Disabilities & & & 0.001 \\
\hline Yes & $89(17.9)$ & $58(22.6)$ & \\
\hline No & $391(78.8)$ & $176(68.5)$ & \\
\hline Missing & $16(3.2)$ & $23(8.9)$ & \\
\hline Walking disability & & & $<0.001$ \\
\hline Walks without help & $373(75.2)$ & $129(50.2)$ & \\
\hline Totally dependent for transfer & $29(5.8)$ & $42(16.3)$ & \\
\hline Needs assistance for transfer & $55(11.1)$ & $37(14.4)$ & \\
\hline Missing & $39(7.9)$ & $49(19.1)$ & \\
\hline
\end{tabular}

Table 3 DHD features

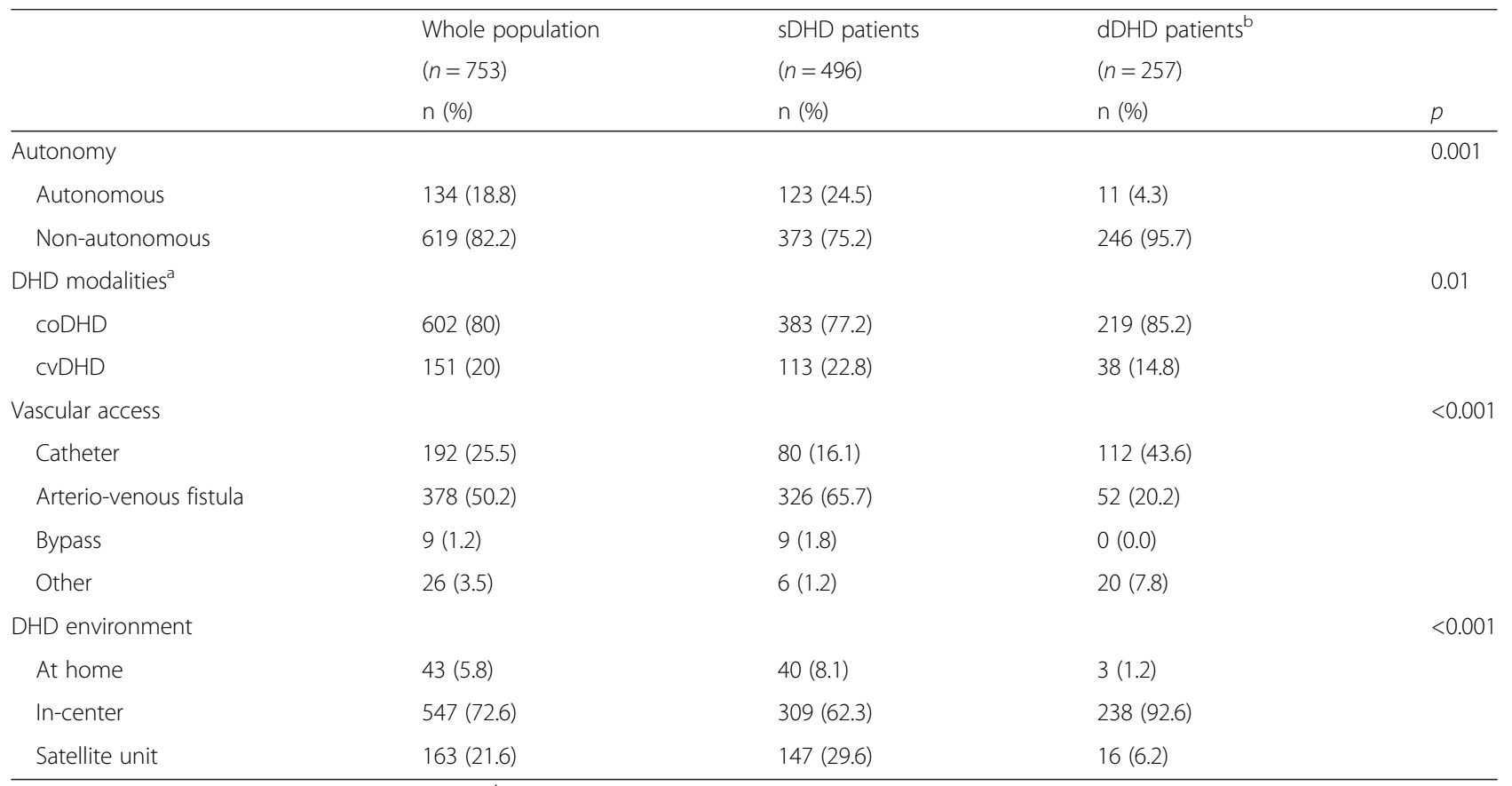

acoDHD: conventional DHD, cvDHD convective DHD, ${ }^{\mathrm{b}} \mathrm{sDHD}$ : patients who switched to DHD after other dialysis modalities; dDHD: patients who started directly with DHD 

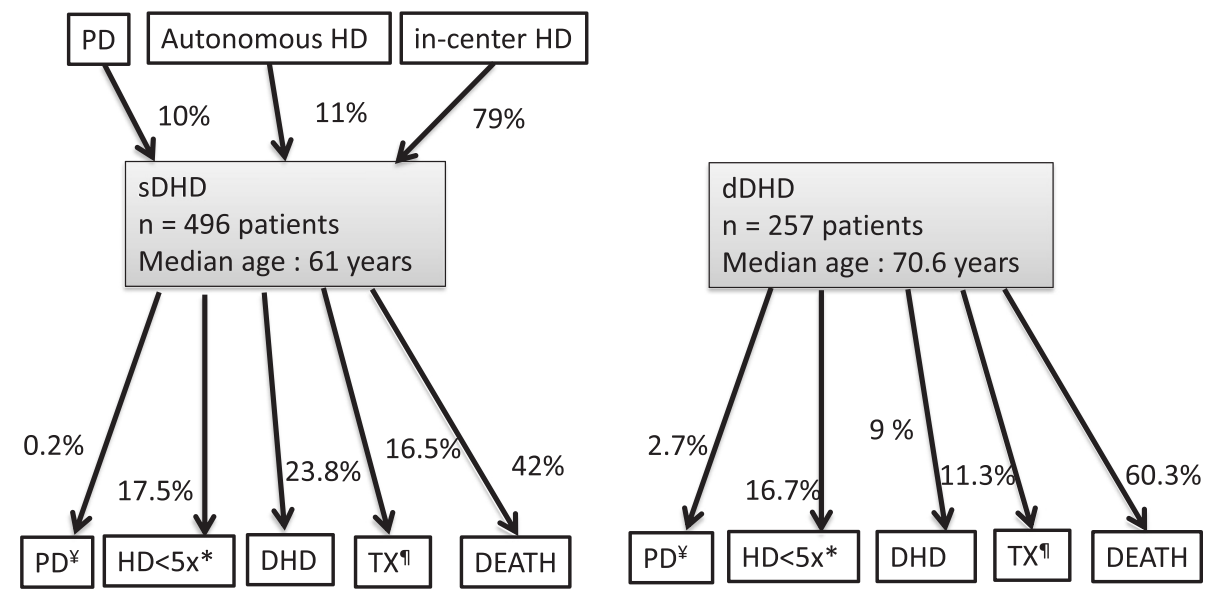

Fig. 1 Patients' treatment trajectories and outcome, by subgroups (sDHD: patients who switched to DHD after other dialysis modalities; dDHD: patients who started directly with DHD). ${ }^{*}$ PD: Peritoneal Dialysis; ${ }^{*} H D<5 x$ : Hemodialysis <5sessions/week; "TX: transplantation

DHD treatment switches. Therefore, and differently from previous studies that only described the first RRT modality and/or the length of the pre-DHD period $[16,18,22,28,33]$, we could analyze and describe all the RRT modality changes before switching to DHD.

We extracted from the REIN registry information on several comorbidities in order to precisely describe the clinical status of patients on DHD. We found that diabetes (38.6\% of all patients), cardiovascular diseases $(60 \%)$ and other comorbidities (respiratory disease: $15.4 \%$, active malignancy: $13.4 \%$, walking disabilities: $21.6 \%$ ) are frequent among French patients undergoing DHD. Previous studies focused mainly on cardiac functions $[8,16,25,26]$ and less frequently on other comorbidities [22, 27, 28, 30, 34], such as diabetes. Indeed, cardiovascular complications are the leading cause of mortality in patients with ESRD and the usual reason for proposing DHD. Moreover, previous studies reported lower percentages of patients on DHD with comorbidities: between 19 and $32 \%$ for diabetes [27, 28], and between 12 and $31 \%$ for cardiovascular diseases [27, 34]. In addition, our study indicates that French patients on DHD are older (mean age: 62 years) than patients in previous studies that assessed the effect of DHD on survival (mean age: from 35.6 to 55.8 years) [27, 35]. These findings may in part explain the higher mortality rate among patients undergoing DHD compared with conventional HD ( $\mathrm{HR}=1.3 ; p=0.034)$ reported by Suri and colleagues [27] and in disagreement with previous reports [22, 28-30,33]. Indeed, our study highlights that a large proportion of French patients on DHD are older and suffer from comorbidities, differently from the patients included in other works. Inversely, they accessed more to renal transplantation. Comparison with a similar population of patients undergoing DHD is now essential to definitively conclude on the survival benefit associated with DHD.
Patients in the dDHD group were more often dialyzed via a catheter $(43.6 \%)$ than those in the sDHD group (20.4\%) and started more frequently the treatment in emergency conditions (57\% vs $28 \%$ ). Starting DHD in an emergency situation often requires dialysis via a catheter. This could explain why arterio-venous fistulae were less common in our population (35.6\%) compared with previous studies where vascular access by arterio-venous fistula was used in $63 \%[18 ; 27]$ to $89 \%$ [35] of patients. Moreover, $20 \%$ of all our patients had albumin levels $<30 \mathrm{~g} / \mathrm{dl}$ and $31 \%$ hemoglobin levels $<10 \mathrm{~g} / \mathrm{dl}$, suggesting that our population is predisposed to malnutrition $[21,23]$ and anemia $[5,21,24]$. The finding that 48 and $33.5 \%$ of patients in the dDHD group had low hemoglobin and albumin levels, respectively, indicates, as reported in previous studies [9, 18, 21, 24, 36], that patients started DHD as an emergency because of their poor medical status which did not allow proposing thriceweekly HD with long sessions. Our results showed that patients who started directly with DHD presented a higher risk of mortality ( $\mathrm{HR}=2.44 ; 95 \% \mathrm{CI}$ : $1.91-3.11)$, but paradoxically they had a better access to renal transplantation $(\mathrm{HR}=2.03$; 95 \% CI: 1.38-3.0). These results suggested that profiles of DHD patients in France are heterogeneous: dDHD is the first RRT of old and frail patients as well as younger ones in better medical conditions.

The association between DHD and biological parameters was impossible to measure in our study. Nevertheless, it has been reported that DHD improves the control of hypertension [26]. DHD is also associated with improved fluid and phosphorus management and inflammatory factors [37]. No negative impacts of DHD on residual renal function have been observed [38]. Arterio-venous fistula is the favorite vascular access for DHD [18], and no statistically significant differences in vascular access dysfunction or permanent failures among 
DHD patients compared to conventional HD ones were reported [39]. Finally, improvements of quality of life with DHD have been largely studied $[4,8,10,11,20,21]$.

In the literature, the RRT trajectory of patients on DHD has not been well described. In our study, patients in the sDHD group had mainly thrice-weekly HD (81\%) or PD (10 \%) before switching to DHD. Only a third of all our patients started directly with DHD. Among the 496 French patients who switched to DHD, $21 \%$ had autonomous dialysis requiring little nurse assistance and therefore had fewer constraints than patients dialyzed in outpatient units. Moreover, younger patients had often a past history of autonomous dialysis before starting DHD. Dialysis at home is associated with a better quality of life and self-rehabilitation [6] and it is often proposed to young patients in good clinical conditions $[6,33,36]$. Younger patients dialyzed at home have fewer comorbidities [28] and more access to renal transplantation than older patients [22]. These observations could explain the association of DHD with improved patient survival. Indeed, these studies included patients in quite good clinical conditions who expected to maintain their social and professional lives, while being dialyzed every day at home [4, 22, 28].

In France, the most frequently prescribed DHD regimen is HD (six 3 h-sessions per week). This protocol has been extensively assessed and it is considered the best choice $[4-6,24]$ to limit the large fluctuations of body fluid volumes caused by thrice-weekly $\operatorname{HD}[4,24]$. Our results show that long nocturnal hemodialysis is rarely used in France. Indeed, only $0.9 \%$ of all patients underwent five to six night sessions of more than five hours/each per week. Nocturnal hemodialysis at home is much developed in Canada and Australia to overcome the geographical isolation of dialyzed patients [40]. Such patients are remote-monitored during the night and alerted if a problem that needs their intervention arises $[23,36]$. Home dialysis requires specific equipment and organization. On the other hand, in France, there are many dialysis facilities with satellite dialysis units [41] to meet the patients' demands in all regions and to avoid patients' isolation as observed in Canada and Australia.

The provision of care for patients in dialysis has an important economic impact on the Health Insurance in France as in the whole world. Costs associated with medical supplies are more important for in-center DHD $[4,42,43]$ than out-center or home HD due to staff and transport costs (reimbursed in France) [24, 44]. However, the development of low-flux machines at home may reduce the costs of DHD.

The main limitation of our study is the lack in the REIN registry of the medical reasons to explain the nephrologist's decision to start or to switch a patient to DHD, differently from the USRDS registry where such reasons are described. Moreover, data from REIN didn't allow us to evaluate the quality of life of patients included in the study.

\section{Conclusions}

Our analysis of the demographic/clinical features and treatment trajectories of 753 French patients on DHD shows that in France, DHD is administered to aged patients with multiple comorbidities and high mortality and also to relatively younger patients on the waiting list for renal transplantation. The heterogeneity of the patients' profiles suggests that DHD indications in France are various. Moreover, the data on the patients' demographic and clinical characteristics and on their initial RRT trajectories could be further used to analyze the association between DHD and patient survival by taking into account their comorbidities and access to renal transplantation.

\section{Additional file}

Additional file 1: Supplementary material. Figure S1. Age distribution of patient at DHD initiation. Figure S2. (a,b). Survival curves of patients by subgroups (trajectory, median age combined with trajectory). Table S1. Factors associated with survival. Figure S3. $(a, b)$. Cumulative incidence function for the access to renal transplantation patients by subgroups (trajectory, median age combined with trajectory). Table S2. Factors associated with renal transplantation. (DOCX $100 \mathrm{~kb}$ )

\section{Abbreviations}

$\mathrm{dDHD}$, starting directly with $\mathrm{DHD}$; $\mathrm{DHD}$, daily hemodialysis; ESRD, end stage renal disease; $H D$, hemodialysis; $H R$, hazard ratio; $I Q R$, interquartile range; $P D$, peritoneal disease; RRT, renal replacement therapy; $S D H D$, starting with other dialysis before switching to DHD

\section{Acknowledgments}

We would like to acknowledge all REIN registry participants including the professionals who collected the data.

\section{Funding}

This study was supported by grants from the French Biomedicine Agency. The funder participates to data collection.

\section{Availability of data and materials}

The access to national data is regulated by a scientific committee of French Biomedecine Agency which analyzes each request. In this context, data available upon request. If readers need information about the data of the REIN registry, they can contact Dr. Cecile Couchoud (cecile.couchoud@biomedecine.fr) who coordinates the REIN at the national level.

\section{Authors' contributions}

AP contributed to conception and design of the study, conducted all statistical analyses, interpreted results and wrote the entire mainbody of this original article. SB contributed to conception and design of the study and helped to revise the manuscript. CC contributed to conception and design, to the acquisition of data and revised the manuscript. CV contributed to the conception and design of the study and revised the manuscript. AK and CB participated to data collection and provided general support to the study. And finally, all authors read and approved the final manuscript for publication.

Competing interests

The authors declare that they have no competing interests.

Consent for publication

Not applicable. 


\section{Ethics approval and consent to participate}

Subjects involved in our study were extracted from the French REIN registry which received agreement from the CNIL (Commission Nationale de I'Information et des Libertés) in 2010 (agreement number: 903188 Version 3). Verbal informed consent to participate was obtained from all subjects involved. This study approved by the French Biomedecine Agency included patients' informations which have been anonymized and de-identified directly in the database and before the extraction for analysis.

\section{Author details}

${ }^{1}$ EHESP Rennes, Sorbonne Paris Cité, Rennes, France. ${ }^{2}$ Université Rennes 1 , UMR CNRS 6290, Rennes, France. ${ }^{3}$ EHESP Rennes, Sorbonne Paris Cité, EA MOS, Rennes, France. ${ }^{4}$ Association AURA, Paris, France. ${ }^{5} \mathrm{CHU}$ Caen, Service de néphrologie, Caen, France. ${ }^{6}$ Université de Caen Normandie, 1086 INSERM, Caen, France. 'Registre REIN, Agence de la biomédecine, Saint Denis La Plaine, France. ${ }^{8} \mathrm{CHU}$ Pontchaillou, Service de néphrologie, Rennes, France.

Received: 1 February 2016 Accepted: 14 June 2016

Published online: 29 July 2016

\section{References}

1. U.S. Renal Data System. USRDS 2012 Annual Data Report: Atlas of Chronic Kidney Disease and End-Stage Renal Disease in the United States, National Institutes of Health, National Institute of Diabetes and Digestive and Kidney Diseases, Bethesda, MD. 2012.

2. Lassalle M, Ayav C, Frimat $L$, Jacquelinet $C$, Couchoud $C$. The essential of 2012 results from the French Renal Epidemiology and Information Network (REIN) ESRD registry. Nephrol Ther. 2015;11(2):78-87. doi:10.1016/j.nephro. 2014.08.002.

3. Cambi V, Savazzi G, Arisi L, et al. Short Dialysis Schedules (SDS)-Finally Ready to Become a Routine? Proc Eur Dial Transpl Ass. 1975;11:112-20. 1975.

4. Blagg CR, Ing TS, Berry D, Kjellstrand CM. The History and Rationale of Daily and Nightly Hemodialysis. In: Lindsay RM, Buoncristiani U, Lockridge RS, Pierratos A, Ting GO, editors. Contributions to Nephrology. 2004. p. 1-9.

5. Kjellstrand CM, Evans RL, Petersen RJ, Shideman JR, Von Hartitzsch B, Buselmeier TJ. The " unphysiology » of dialysis: A major cause of dialysis side effects? Hemodial Int. 2004;8(1):24-9.

6. Kooistra MP. Frequent prolonged home haemodialysis: three old concepts, one modern solution. Nephrol Dial Transplant. 2003;18:16-9.

7. Hakim RM, Saha S. Dialysis frequency versus dialysis time, that is the question. Kidney Int. 2014;85:1024-9.

8. Culleton BF, Asola MR. The impact of short daily and nocturnal hemodialysis on quality of life, cardiovascular risk and survival. J Nephrol. 2011;24(4):405-15.

9. Twardowski Z. Effect of long-term increase in the frequency and/or prolongation of dialysis duration on certain clinical manifestations and results of laboratory investigations in patients with chronic renal failure. Hemodial Int. 2004;8(1):30-8.

10. Buoncristiani U. Fifteen years of clinical experience with daily haemodialysis. Nephrol Dial Transplant. 1998;13 suppl 6:148-51.

11. Stokes JB. Consequences of frequent hemodialysis: comparison to conventional hemodialysis and transplantation. Trans Am Clin Climatol Assoc. 2011:122:124-36.

12. Mc Causland FR, Brunelli SM, Waikar SS. Dialysis Dose and Intradialytic Hypotension: Results from the HEMO Study. Am J Nephrol. 2013;38:388-96.

13. Eknoyan G, Beck GJ, Cheung AK, et al. Effect of dialysis dose and membrane flux in maintenance hemodialysis. N Engl J Med. 2002;347(25):2010-9.

14. Locatelli F, Buoncristiani U, Canaud B, Köhler H, Petitclerc T, Zucchelli P. Dialysis dose and frequency. Nephrol Dial Transplant. 2005;20(2):285-96.

15. Bonomini V, Mioli V, Albertazzi A, Scolari P. Daily-dialysis programme: indications and results. Nephrol Dial Transplant. 1998;13(11):2774-7.

16. Katopodis KP, Dounousi E, Challa A, Pappas K, Kalaitzidis R, Siamopoulos KC. Switch From Conventional to Every Other Day Hemodialysis: A Comparison Pilot Study. ASAIO J. 2009;55:41-6.

17. Teschan PE, Baxter CR, O'Brien TF, Freyhof JN, Hall WH. Prophylactic hemodialysis in the treatment of acute renal failure. J Am Soc Nephrol. 1998:9(12):2384-97.

18. Toussaint ND. Review: Differences in prescription between conventional and alternative haemodialysis. Nephrology. 2010;15:399-405.

19. Kjellstrand CM, Ing T. Daily Hemodialysis: History and Revival of a Superior Dialysis Method. ASAIO J. 1998;44(3):117-22.
20. Punal J, Lema LV, Sanhez-Guisande D, Ruano-Ravina A. Clinical effectiveness and quality of life of conventional hemodialysis versus short daily hemodialysis: a systematic review. Nephrol Dial Transplant. 2008;23:2634-46.

21. Vos PF, Zilch O, Kooistra MP. Clinical Outcome of Daily Dialysis. Am J Kidney Dis. 2001;37(1):99-102

22. Kjellstrand CM, Buoncristiani U, Ting G, et al. Short daily haemodialysis: survival in 415 patients treated for 1006 patients-years. Nephrol Dial Transplant. 2008;23:3283-9.

23. Pierratos A, Ouwendyk M, Francoeur R, et al. Nocturnal hemodialysis: threeyear experience. J Am Soc Nephrol. 1998;9(5):859-68.

24. Lindsay R, Nesrallah G, Suri R, Garg A, Moist L. Is more frequent hemodialysis beneficial and what is the evidence? Curr Opin Nephrol Hypertens. 2004;13(6): 631-5.

25. Chan CT, Greene T, Chertow GM, et al. Determinants of left ventricular mass in patients on hemodialysis: Frequent Hemodialysis Network (FHN) Trials. Circ Cardiovasc Imaging. 2012;5:251-61.

26. Chan CT, Chertow GM, Daugirdas JT, et al. Effects of daily hemodialysis on heart rate variability: results from the frequent hemodialysis network (FHN) daily trial. Nephrol Dial Transplant. 2014;29(1):168-78.

27. Suri RS, Lindsay RM, Bieber BA, et al. A multinational cohort study of incenter daily hemodialysis and patient survival. Kidney Int. 2013;83:300-7.

28. Kjellstrand $C M$, Buoncristiani $U$, Ting $G$, et al. Survival with short-daily hemodialysis: Association of time, site, and dose of dialysis. Hemodialysis Int. 2010;14:464-70.

29. Nesrallah GE, Lindsay RM, Cuerden MS, et al. Intensive Hemodialysis Associates with Imporved Survival Compared with Conventional Hemodialysis. J Am Soc Nephrol. 2012;23:696-705.

30. Johansen $\mathrm{KL}$, Zhang $\mathrm{R}$, Huang $\mathrm{Y}$, et al. Survival and hospitalization among patients using nocturnal and short daily compared to conventional hemodialysis: a USRDS study. Kidney Int. 2009;76:984-90.

31. Kolko A, Honnoré $N$, Roche $S$, Vigneau $C$, Lassalle $M$, the REIN registry. Clinical characteristics and care indicators for dialysis patients. Néphrologie \& Thérapeutique. Rapport annuel. 2013.

32. Couchoud C, Stengel B, Landais $P$, et al. The renal epidemiology and information network (REIN): a new registry for end stage renal disease in France. Nephrol Dial Transplant. 2006;21:411-8.

33. Woods JD, Port FK, Orzoi S, et al. Superior patient and technique survival with very high standard $\mathrm{Kt} N$ in quotidian home hemodialysis. Kidney Int. 1999;55:2467-76.

34. Weinhandl ED, Nieman KM, Gilbertson DT, Collins AJ. Hospitalization in Daily Home Hemodialysis and Matched Thrice-Weekly In-Center Hemodialysis Patients. Am J Kidney Dis. 2015;65(1):98-108.

35. Martins Castro MC, Luders C, Elias RM, Abensur H, Romão Junior JE. Highefficiency short daily haemodialysis-morbidity and mortality rate in a longterm study. Nephrol Dial Transplant. 2006;21(8):2232-8.

36. Piccoli GB, Bermond F, Mezza E, et al. Vascular access survival and morbidity on daily dialysis: a comparative analysis of home and limited care haemodialysis. Nephrol Dial Transplant. 2004;19:2084-94.

37. Ayus JC, Mizani MR, Achinger SG, Thadhani R, Go AS, Lee S. Effects of short daily versus conventional hemodialysis on left ventricular hypertrophy and inflammatory markers: a prospective, controlled study. J Am Soc Nephrol. 2005:16:2778-88.

38. Daugirdas JT, Greene T, Rocco MV, et al. Effect of frequent hemodialysis on residual kidney function. Kidney Int. 2013:83:949-58.

39. Suri RS, Nesrallah GE, Mainra R, Garg AX, Lindsay RM, Greene T, Daugirdas JT. Daily Hemodialysis: a systematic review. Clin J Am Soc Nephrol. 2006;1:33-42.

40. Agar JW. Nocturnal haemodialysis in Australia and New-Zealand. Nephrol. 2005;10:222-30

41. Bayat S, Macher MA, Couchoud C et al. Individual and Regional Factors of Access to the Renal Transplant Waiting List in France in a Cohort of Dialyzed Patients. Am J Transplant. 2015;15(4):1050-60.

42. Lee CP, Zenios SA, Chertow GM. Cost-effectiveness of frequent in-center hemodialysis. J Am Soc Nephrol. 2008;19:1792-7.

43. McFarlane PA. Reducing hemodialysis costs: conventional and quotidian home hemodialysis in Canada. Semin Dial. 2004;17(2):118-24.

44. Couchoud C, Couillerot AL, Dantony E, Elsensohn MH, Labeeuw M, Villar E, Ecochard R, Bongiovanni I. Economic impacts of a modification of the treatment trajectories of patients with end stage renal disease. Nephrol Dial Transplant. 2015;30(12):2054-68. 